\title{
A RELAÇÃO ENTRE A RELIGIÃO CIVIL E A IDEIA DE TOLERÂNCIA NO PENSAMENTO DE JEAN- JACQUES ROUSSEAU
}

\section{LAS RELACIONES ENTRE LA RELIGIÓN CIVIL Y LA IDEIA DE TOLERANCIA EN EL PENSAMIENTO DE JEAN- JACQUES ROUSSEAU}

Laisla Pereira Santos ${ }^{1}$

(laisla-laislinha2009@hotmail.com)

\begin{abstract}
RESUMO
Rousseau, em Do Contrato Social, apresenta uma "nova" religião, nomeando-a de civil. Essa religião, aplicada à esfera política, visa à preservação do espírito público; mais precisamente, ela expressa princípios de sociabilidade, por se fazer necessária para a conservação dos vínculos sociais. Rousseau propõe, assim, a religião civil como recurso político, de modo a prevenir com ela o enfraquecimento das associações que compõem o vigor do Estado. O objetivo deste trabalho é elucidar a importância dessa religião para a sociedade do Contrato - desvendando as pretensões do autor ao elaborar um código moral que fortaleça os liames sociais -, analisando, especialmente, a relação entre ela e a ideia de tolerância.
\end{abstract}

Palavras-chave: Contrato Social. Religião Civil. Tolerância. Rousseau.

\section{RESUMEN}

Rousseau, en Del Contrato Social, presenta una "nueva" religión, nombrándola de civil. Esta religión, aplicada en la esfera política, tiene como objetivo la preservación del espíritu público; más precisamente, ella expresa principios de sociabilidad, por hacerse necesaria para la conservación de los vínculos sociales. Siendo así, Rousseau propone la religión civil como recurso político, con el fin de prevenir con ella el debilitamiento de las asociaciones que componen el vigor del Estado. El objetivo de este trabajo es elucidar la importancia de esa religión para la sociedad del Contrato - desvelando las pretensiones del autor al elaborar un código moral que fortalezca los vínculos sociales -, analizando, especialmente, la relación entre ella y la idea de tolerancia.

Palabras clave: Contrato Social. Religión Civil. Tolerancia. Rousseau.

\section{O EMBRIÃO}

\footnotetext{
${ }^{1}$ Graduanda em Filosofia pela Universidade de Brasília (UnB).

CV Lattes: http://lattes.cnpq.br/1498842446567925.

ORCID: https://orcid.org/0000-0002-9443-0559.
} 
Ao lermos o Capítulo VIII, intitulado "Da religião civil", do Livro IV Do Contrato Social, vemos de maneira mais detalhada o embrião de uma ideia já esboçada na "Carta de JJ. Rousseau ao Senhor de Voltaire”, enviada no dia 18 de agosto de 1756, retirada da obra Carta a Christophe de Beaumont e outros escritos sobre a religião e a moral. Há nesse embrião o princípio da ideia de religião civil, sendo possível notar que o filósofo genebrino utiliza outros termos para designá-la:

Gostaria, então, que houvesse em cada Estado um código moral ou uma espécie de profissão de fé civil, contendo, positivamente, as máximas sociais as quais cada um seria obrigado a admitir, e negativamente, as máximas fanáticas as quais seria obrigado a rejeitar, não como ímpias, mas como sediciosas. Assim, toda religião que pudesse estar de acordo com o código seria admitida, toda religião que discordasse dele seria proscrita, e cada um seria livre para não ter outra a não ser o próprio código. (ROUSSEAU, 2005, p. 135)

Rousseau apresenta, inicialmente, como tal religião atuaria perante o corpo político: sua essência é, em primeiro lugar, garantir uma convivência pacífica entre os diferentes tipos de ritos e cultos. Ao criar esse código moral, o soberano salvaguarda o Estado, extirpando as crenças nocivas que abalam os vínculos sociais - o soberano, como aponta Rousseau, deve ter certa precaução ao analisar quais das religiões são prejudicais para o espírito público, pois ele age em prol da paz no corpo social.

Assim, Rousseau, ao conceber tal código, abre um espaço que envolve a pluralidade de crenças, lembrando, entretanto, que não se trata de uma aceitação irrestrita dessas crenças por parte do soberano, pois uma de suas funções é preservar a ordem social, eliminando sobretudo os cultos que ferem as regras de sociabilidade. Na concepção do filósofo, a religião não é algo descartável, sendo possível uma conciliação entre ela e o Estado: na sociedade idealizada por Rousseau, o Estado não seria completamente neutro, mas tampouco imporia qual religião deve prevalecer. Na carta dirigida a Voltaire, vemos, portanto, os primeiros passos de Rousseau ao estabelecer a ideia de religião civil, apresentando-a como uma máxima social a que todos devem obedecer em virtude da felicidade pública.

\section{A RELIGIÃO CIVIL EM DO CONTRATO SOCIAL}


A religião civil se vê lançada a vários desafios, começando mesmo a partir de sua própria criação, pois a proposta rousseauniana para a criação dessa religião foi retirada de duas outras religiões, citadas na obra Do Contrato Social. Efetivamente, Rousseau apresenta três tipos de religião no decorrer de seu tratado político, sendo elas a religião do homem, a religião do cidadão e a religião do padre.

A primeira religião é voltada para a sociedade em geral, visando a moral estabelecida pelo Evangelho; ela é desprovida de uma instituição religiosa, porque Deus se comunicaria com o homem através do coração, sem o intermédio de terceiros. Sendo assim, ela está para além das sociedades particulares e tem por intuito reunir todos os homens como irmãos a fim de que haja respeito mútuo entre eles. Mas, de acordo com Rousseau, tal religião possui uma desvantagem - por afastar os corações dos cidadãos do Estado -, pois se negligenciam as coisas terrenas em vista de uma vida celestial. A religião do homem, portanto, é boa no sentido de fazer com que os homens se reconheçam como irmãos - promovendo, desse modo, uma convivência pacífica entre eles -, e ruim no sentido de não se preocupar com as coisas deste mundo.

Já a religião do cidadão é voltada para uma sociedade particular, pois cada país determina seu culto; ela é, assim, nacional e exclusiva e, por conseguinte, seu lado negativo é não aceitar cultos estrangeiros, adotando uma postura intolerante para com as demais crenças. Em contrapartida, ela possui um lado positivo "por unir o culto divino ao amor das leis e porque, fazendo da pátria objeto da adoração dos cidadãos, lhes ensina que servir o Estado é servir o deus tutelar" (ROUSSEAU, 1987, p. 141). Essa religião é vantajosa, por um lado, pois faz com que os homens amem as leis estabelecidas pelo Estado e as obedeçam, uma vez que, servindo ao Estado, os homens também estarão servindo à divindade; por outro lado, é desvantajosa por não aceitar crenças que diferem da dela, tornando os homens sanguinários, cruéis e intolerantes. Segundo Rousseau, tal religião "torna-os crédulos, supersticiosos, e submerge o verdadeiro culto da Divindade num cerimonial vão" (ROUSSEAU, 1987, p. 141).

Por último, temos a religião dos padres, acerca da qual Rousseau tece suas críticas, pois habita nela certo tipo de conflito e desarmonia entre a esfera religiosa e a política, já que uma quer se sobrepor à outra. Nessa religião, puramente perigosa, o homem é colocado diante de incoerências - há dois chefes e duas ordens, o que o impede de ser devoto e cidadão -, por não se proporcionar um equilíbrio entre o âmbito político e o religioso.

O filósofo genebrino toma aspectos positivos de duas concepções de religião, a do homem e a do cidadão, retirando-lhes os aspectos negativos, para 
construir uma religião que preze pelos sentimentos de sociabilidade do homem, chamando-a de religião civil. Ela é o palco em que há uma harmonia entre a política e a religião, já que seu propósito é fazer com que os cidadãos cumpram com seus deveres civis para manter o ordenamento do corpo social. Tal religião é elemento crucial para o desempenho do espírito público; ela não é exatamente uma religião como as demais, pois é desprovida de ritos e altares, tentando encontrar aspectos em comum entre os diferentes tipos de crenças.

Qual seria a intenção de Rousseau ao criar essa religião? Infere-se, a partir de seus escritos, que a religião civil é criada para promover uma convivência pacífica entre os indivíduos. Curiosamente, seus dogmas civis previnem que o corpo social entre em colapso, já que seu objetivo é desarticular seitas que tomam por dogma a intolerância, pois tais acabam por abalar as estruturas sociais. A religião civil é uma espécie de profissão de fé que visa à asseguração das regras de sociabilidade para que o cidadão exerça seus deveres. Nesse contexto, aqueles que não obedecerem a elas poderão ser banidos, exilados ou mesmo condenados à morte.

Os dogmas da religião civil são "a existência da Divindade poderosa inteligente, benfazeja, previdente e provisória; a vida futura; a felicidade dos justos; os castigos dos maus; a santidade do contrato social e das leis" (ROUSSEAU, 1987, p. 144). Nessa passagem, Rousseau encontra aspectos em comum entre as variadas crenças, visto que a medida tomada pelo soberano serve para conter as divergências religiosas, vislumbrando uma convivência pautada pelo respeito e pela tolerância. Preocupado com a manutenção do Estado, o filósofo cria um código moral, ou, se quisermos, a religião civil, para não haver uma cisão entre Estado e religião; essa relação é vista como um palco harmônico, no qual existe uma conciliação entre as duas esferas. Por isso, Rousseau procura trabalhar com essas duas dimensões unidas, pois o Estado, a seu ver, necessita do aparato religioso, na medida em que ele ensina a seus servos a obediência. Com efeito, as crenças religiosas exercem uma função importante na conduta dos cidadãos.

No decorrer de sua obra, o referido autor explicita melhor como seria possível a conciliação entre as duas dimensões. Já de início, deixemos claro que o soberano não determina a religião que regerá todo o corpo social, já que a religião civil anula a crença particular somente quando ela é nociva para o Estado. Em outras palavras, a religião civil não apenas une todas as crenças ao tentar encontrar um substrato comum, como também, a partir de seu quinto dogma, preza pela obediência e determina que seus súditos cumpram com seus deveres civis; além disso, a religião civil tem por função examinar todas 
as religiões para poder admiti-las, proibindo a inserção de doutrinas intolerantes, as quais ferem as regras e as máximas sociais. De modo geral, a religião civil evita a ocorrência de atritos religiosos.

Segundo Thomas Kawauche (2007, p. 12), “A religião civil só diz respeito à religiosidade privada na medida em que esta se manifesta na conduta dos indivíduos em sociedade". Não cabe ao Estado, portanto, escolher ou determinar a crença religiosa de seus súditos a não ser quando elas ferem o código moral prescrito pelo mesmo, visto que o interesse do soberano reside nas ações que mantêm a vitalidade das leis. O historiador Jorge Grespan aborda o caráter da religião civil dizendo:

[...] por isso a "vontade geral" não é a soma dos contratos entre indivíduos na sua vida particular, mas tem uma existência pública, como uma consciência do todo presente em cada cidadão. Ela devia ser cimentada, então, por uma espécie de "religião civil", em que a própria sociedade é adorada e cultuada pelos seus membros, estabelecendo sua lealdade pelo sentimento de a ela pertencerem. (GRESPAN, 2008, p. 72)

A religião civil, portanto, desperta as virtudes cívicas dos cidadãos, isto é, suscita neles o respeito, a tolerância e o zelo pelo espírito público. Sua criação é voltada para a manutenção da ordem cívica, protegendo-a de grandes ameaças sediciosas. Em suma, a sociedade seria o objeto de adoração dessa religião; o indivíduo que possui essa consciência coletiva professa os preceitos advindos do código moral e a eles obedece.

\section{TOLERÂNCIA}

Examinaremos agora a relação entre a religião civil e a noção de tolerância. Obviamente, não podemos deixar de lembrar que tal religião é peça-chave para a manutenção do Estado, uma vez que seus dogmas agem em vista de um culto público, o qual modera as divergências religiosas:

Ora, importa ao Estado que cada cidadão tenha uma religião que o faça amar seus deveres; os dogmas dessa religião, porém, não interessam nem ao Estado nem a seus membros, a não ser enquanto se ligam à moral e aos deveres que aquele que a professa é obrigado a obedecer em relação a outrem. Quanto ao mais, cada um pode ter as opiniões que lhe aprouver, sem que o soberano possa tomar conhecimento delas, pois, como não chega sua competência ao outro mundo, nada 
tem a ver com o destino dos súditos na vida futura, desde que sejam bons cidadãos nesta vida. (ROUSSEAU, 1985, p. 141)

Nessa passagem, Rousseau deixa claro que a preferência religiosa cabe somente ao foro íntimo de cada um, desde que as suas escolhas não interfiram na manutenção do espírito público. Diante disso, o soberano não deixa de excluir certas doutrinas que fazem mal para o corpo político, ou seja, não há uma "abstenção" integral por parte dele. Kawauche, a respeito dessa passagem, diz:

E isso está em completo acordo com o pensamento político de nosso autor, que não coloca em questão as doutrinas em si mesmas, mas a necessidade de que cada cidadão promova a coesão do corpo político sendo tolerante em relação às crenças alheias, uma vez que a intolerância - seja ela civil ou teológica - apresenta o efeito nocivo de favorecer o surgimento de partidos e, por conseguinte, o enfraquecimento dos vínculos sociais. (KAWAUCHE, 2010, p. 125-166)

A noção de tolerância rousseauniana se dá por meio das máximas da religião civil. Nesse sentido, o Estado tolerante ao qual Rousseau se refere não é uma espécie de aceitação absoluta de todo e qualquer tipo de religião, pois há restrições no que concerne a algumas dessas doutrinas. O filósofo genebrino, temendo por uma guerra religiosa, toma tal precaução ao construir uma religião civil que contenha artigos que salvaguardam o espírito social e a paz. O que debilita os liames sociais, para Rousseau, são as doutrinas intolerantes, pois podem causar grande efeito civil. Ao voltarmos à carta dirigida a Voltaire em 1756, vemos que Rousseau definiu os intolerantes:

[...] todos aqueles que imaginam que um homem de bem deve necessariamente acreditar em tudo o que eles acreditam, e condenam impiedosamente o que não pensa como eles próprios. (ROUSSEAU, 2005, p. 135)

Em outras palavras, intolerantes são aquele que enfraquecem as relações sociais entre os homens em benefício de sua religião, aqueles que não aceitam uma doutrina contrária às suas. A intolerância rompe com a vitalidade da ordem social. No Livro IV de Emílio ou Da Educação, Rousseau fala das consequências da intolerância:

Longe de esclarecer as noções do grande Ser, vejo que os dogmas particulares as embrulham; que longe de as enobrecer, eles as aviltam; que aos mistérios inconcebíveis que o cercam acrescentam contradições absurdas; que tornam o homem 
orgulhoso, intolerante, cruel; que longe de estabelecer a paz na terra, nela introduzem o ferro e o fogo. Pergunto-me para que tudo isso, sem saber responder. Só vejo nisso os crimes dos homens e as misérias do gênero humano. (ROUSSEAU, 1995, p. 345)

Esses dogmas particulares motivados pela intolerância não desvelam a verdadeira mensagem que o ser divino traz para o entendimento do homem, pois, tomados por esses dogmas, os fanáticos fazem mau uso da razão. Assim, a melhor das religiões é aquela que não pune o homem pelo uso de sua razão, mas sim aquela que ajuda a iluminá-la, pois Deus deu o entendimento para que o homem o use. Para Rousseau, tudo aquilo que foi ensinado desde a infância deve ser submetido ao exame racional.

Ora, quais consequências sofre um indivíduo que não crê nos princípios de sociabilidade fixados pela religião civil e a eles desobedece? De acordo com Rousseau, o soberano,

[...] sem poder obrigar ninguém a crer neles, pode banir do Estado todos os que neles não acreditarem, pode bani-los não como ímpios, mas como insociáveis, como incapazes de amar sinceramente as leis, a justiça, e de imolar, sempre que necessário, sua vida a seu dever. Se alguém, depois de ter reconhecido esses dogmas, conduzir-se como se não cresse neles, deve ser punido com a morte, pois cometeu o maior de todos os crimes - mentiu às leis. (ROUSSEAU, 1985, p. 144)

O indivíduo que não crê nesses dogmas civis é considerado como mau cidadão ou súdito infiel, sendo visto, dessa maneira, como antissocial. A tolerância visa à conservação do Estado, e aqueles que ferem ou renegam tal dogma apresentam grande ameaça para o corpo social. Percebemos, porém, que há diferenças nas respectivas punições, pois só é condenado à morte o indivíduo que fingiu crer nas leis, uma vez já assumida sua crença publicamente. Nesse caso, como ficaria a situação de um ateu? Segundo Kawauche,

\footnotetext{
Nesses termos, podemos apreciar melhor a idéia rousseauniana de que o ateu, assim como qualquer indivíduo insociável, não deve ser tolerado no Estado: por não crer nos dogmas, ele não pode ser "bom cidadão" nem "súdito fiel". Todavia, é preciso entender que, na sociedade do Contrato, o ateu não é condenado à morte por suas opiniões religiosas, isto é, pelo fato de se declarar ateu, mas sim por seu comportamento ofensivo à boa moral e, conseqüentemente, pela ameaça que representa ao bem comum visado no ato fundador do contrato. (KAWAUCHE, 2010, p. 125-166)
}

Aqui, o problema não é o ateísmo em si, mas o mau comportamento em sociedade, pois, se o ateu não segue qualquer religião, ele não seguirá tampouco as 
leis - ou seja, aqueles destituídos de crença religiosa não são capazes de amar e honrar tais leis e a elas obedecer. Esse pensamento está necessariamente implicado na sociedade do Contrato: um indivíduo descrente é compreendido, nesse contexto, como um desobediente cívico.

\section{CONSIDERAÇÕES FINAIS}

A religião, para Rousseau, é nociva quando seus dogmas implicam uma postura intolerante perante uma crença que diverge da sua. Por conta dessa intolerância, o referido autor constrói um tipo de religião que faça jus à noção de tolerância, buscando como propósito um discurso que preze pela conservação do Estado. Destarte, o tema rousseauniano de tolerância nos remete à aceitação dos diferentes tipos de crença, desde que eles não intervenham na ordem estabelecida. Percebe-se, de certa maneira, que tal religião promove uma convivência pacífica entre os cidadãos e, seguindo essa abordagem, o código moral (a religião civil) decide o tolerável e o intolerável. Portanto, a tolerância desempenha um papel fundamental na ordem civil.

Observamos ainda que a religião civil não é como as demais religiões construídas historicamente, sendo proveniente da união entre a religião do homem e a do cidadão. Isso não significa, porém, que ela seja desprovida de um corpo doutrinário, já que seus dogmas consagram as máximas sociais. Dessa forma, o Estado rousseauniano perfeito não é desassociado de uma religião, mas sua religião é puramente civil.

Nossa intenção foi apresentar a importância de tal religião para a sociedade do Contrato, usando como suporte as teses de Kawauche para esclarecer seus principais aspectos. Vê-se que a religião civil ligada à ideia de tolerância fortifica os vínculos sociais. A figura do soberano, em Do Contrato Social, não é imparcial quando se trata de religiões que professam dogmas intolerantes, tomando por precaução ações efetivas que possam coibir o ódio manifestado por elas. O caráter essencial da religião civil é preservar a paz no Estado e estimular o cidadão a exercer seus deveres na terra; logo, tudo aquilo contrário a seus princípios é visto como pernicioso para a manutenção civil. A mencionada religião é um instrumento indispensável para a realização dos propósitos de uma sociedade bem constituída. 


\section{REFERÊNCIAS BIBLIOGRÁFICAS}

GRESPAN, Jorge. Revolução Francesa e Iluminismo. São Paulo: Contexto, 2008.

KAWAUCHE, Thomas. A santidade do contrato e das leis: um estudo sobre religião e política em Rousseau. Dissertação (Mestrado em filosofia). São Paulo, 2007. Faculdade de Filosofia, Letras e Ciências Humanas (USP).

. Tolerância e Intolerância em Rousseau. São Paulo: Alameda, 2010.

ROUSSEAU, Jean-Jacques. Carta ao senhor Voltaire. Carta a Christophe de Beaumont e outros escritos sobre a religião e a moral. Trad. José Oscar de Almeida Marques e outros. São Paulo: Estação Liberdade, 2005.

Do contrato social; Ensaio sobre a origem das línguas; Discurso sobre as ciências e as artes; Discurso sobre a origem e os fundamentos da desigualdade entre os homens. In: Rousseau. Trad. Lourdes Santos Machado. São Paulo: Nova Cultural, 1987. (Col. Os Pensadores)

. Emílio ou Da Educação. Trad. Sérgio Milliet. Rio de Janeiro: Bertrand Brasil, 1995. 